\title{
ARTIGO
}

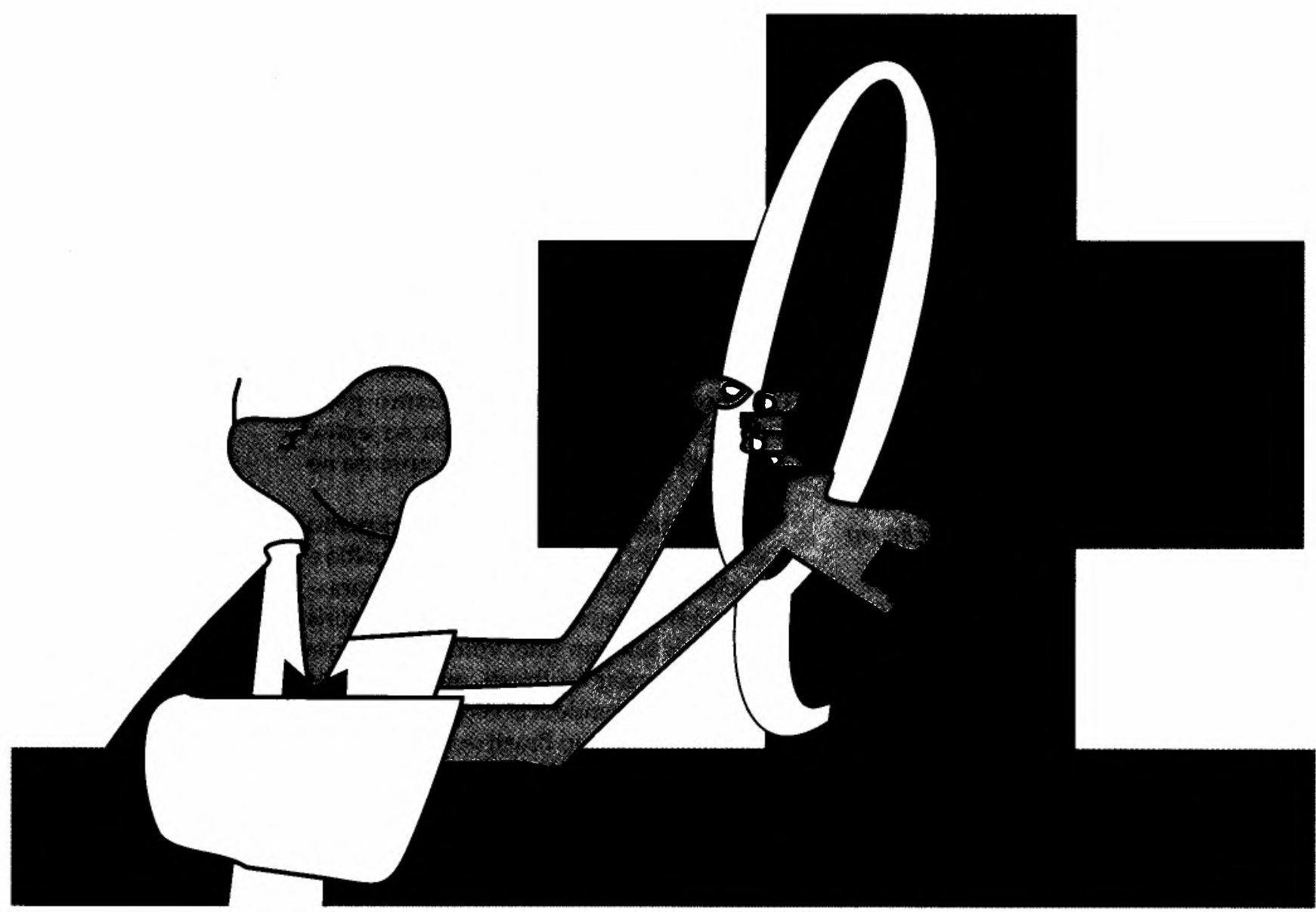

\section{DESENVOLVIMENTO DE RECURSOS HUMANOS, GERÊNCIA DE QUALIDADE E CULTURA DAS ORGANIZAÇÕES DE SAÚDE}

Ana Maria Malik

Professora do Departamento de Administração Geral e Recursos Humanos da EAESP/FGV.

* RESUMO: Administração da Qualidade começa a ser discutida na área de saúde, no Brasil. Por isto, a discussão a respeito da aplicabilidade dos conceitos ao setor, bem como de suas limitações, parece oportuna. Qualidade enquanto conceito é indissociável de alterações na cultura organizacional $e$ de desenvolvimento de recursos humanos, além de precisar considerar aspectos técnicos e parâmetros específicos da gestão setorial. O pequeno número de experiências existentes em serviços de saúde no Brasil e seu curto tempo de desenvolvimento permitem trabalhar mais com dúvidas que com certezas a respeito das perspectivas futuras para este campo de conhecimento.
* PALAVRAS-CHAVE: Administração da qualidade, administração de saúde, cultura organizacional.

* ABSTRACT: TQM - Total Quality Management - is new to Brazilian health organizations. It is important to try to highlight its feasibility and its boundaries within the sector. It is also necessary to point out the strong relationship between TQM, organizational culture and human resources development, as well as the need for new parameters related to throughputs and outcomes. There are still more doubts than actual knowledge related to the ongoing Brazilian experiences in the field.

* KEY WORDS: TQM, health administration, organizational culture.

São Paulo, 32(4): $32-41$ 


\section{INTRODUÇÃO}

Entre as questões relativas à "modernidade" da administração de saúde estão certamente aquelas voltadas ao desenvolvimento de recursos humanos, cultura organizacional e qualidade. Algumas delas, no que diz respeito à administração de maneira geral, estiveram em moda há alguns anos. Sua chegada ao setor saúde foi mais tardia e, até hoje, se mantêm basicamente como assuntos de debate, não tendo chegado ainda à operacionalização. ${ }^{1}$

Como sempre, é necessário distinguir o que é "modismo" ou "receita" de sua operacionalização ou real aplicabilidade para o longo prazo. Desta forma, é desejável,por exemplo, considerar as condições de contorno mais amplas nas quais se insere a organização a respeito da qual se discute qualquer alternativa gerencial, seja ela inovadora ou não. Assim, o discurso geral de desenvolvimento de recursos humanos na área de saúde pode parecer utópico frente às condições nacionais de não priorização do setor ou a sua faixa de remuneração e/ou valorização social frente a outros setores, por mais indispensável que ele seja considerado dentro e fora da área, por políticos, técnicos e usuários. A rigor, caberia perguntar indispensável para que, para cada uma destas categorias.

Cultura organizacional, por sua vez, como boa parte dos temas de moda (e, enquanto tal, bastante divulgados), aparece disseminada nos discursos de profissionais, embora talvez pouco conhecida em seu significado teórico real. Como tantos outros aspectos da teoria organizacional, ela é vista mais como um dado relativamente fixo da realidade, a ser levado em conta e a ser possivelmente superado, que como um instrumento gerencial. Ou seja, aparece como restrição com muito mais freqüência que como algo passível de ser trabalhado, se e quando entendido nas suas reais fronteiras de potencialidades $e$ limitações.

Finalmente, qualidade é palavra de domínio público, trabalhada dentro dos amplos limites daquilo que se considera senso comum. Afinal, mesmo se poucos sabem o que o termo significa, "todo mundo sabe reconhecê-la quando está diante dela" ou "todo mundo sabe quando ela está ausente de determinado produto ou serviço".
Os limites de aceitabilidade são confusos e o conceito é amplo o suficiente para que este atributo seja apregoado com relativa impunidade em relação a qualquer coisa oferecida ao público consumidor. Esta impunidade talvez esteja atualmente reduzida, até mesmo na realidade brasileira, pode-se dizer que muito mais em função do Código de Defesa do Consumidor e de alguns movimentos de consumidores específicos que da consciência de que é direito de qualquer cidadão o acesso a bens ou serviços "de qualidade". Ou seja, numa sociedade em que se tem a vaga noção de que os serviços de saúde não têm a qualidade esperada (desejada?), consome-se o que há ou o que é possível obter. No entanto, como não se trabalha sobre conceitos ou medidas de qualidade, como mudar este quadro?

Mesmo assim, no Brasil dos anos 90 , é necessário algum grau de otimismo para que se possa aceitar o conceito de consumidor quando se fala de saúde, principalmente na área de assistência médico-hospitalar. Embora o acesso universal esteja entre os preceitos constitucionais desde 1988, este é muito mais um anseio que uma realidade. Portanto, para a maioria da população, o consumo em saúde precisaria primeiro existir, para depois ser qualificado. No entanto, isto certamente não invalida a busca da qualidade na área. A rigor, apenas obriga a que, entre os objetivos parciais a atingir, esteja o acesso.

Inegavelmente, os três conceitos que se pretendem analisar neste trabalho estão interligados. Pode-se criar uma cultura organizacional que favoreça a busca incessante da qualidade, e esta é indissociável não apenas das necessidades de treinamento mas, principalmente, daquelas de desenvolvimento de-recursos humanos. Desta forma, imaginar que qualquer destes aspectos possa ser trabalhado de forma isolada no mundo real da administração é ilusório. Na teoria, cada uma costuma ser vista como área de especialidade. No entanto, como o mundo da administração é o mundo real, caso a teoria insista em manter a análise dos conhecimentos específicos, a prática termina por gerar algum tipo de síntese. $O$ que se observa na realidade atual é um somatório de visões não confluentes de conhecimentos. Afinal, a teoria é gerada em função de fatos
1. Por exemplo, uma nota intitulada "A hora e a vez da cultura organizacional", de autoria de Sérgio BatistaZacarelli (Prot. TitulardaFEA - USP) toi publicada na Revista de Administração, 21 (3): 58-9, 1986. Desenvolvimento de Recursos Humanos está presente no discurso e até nas estruturas do setor saúde pelo menos desde a metade dos anos 80 , mas sente-se a falta de suas práticas em qualquer diagnóstico atualizado do setor. Finalmente, embora os escritos de Deming e Juran referentes à Administração da Qualidade também tenham sido divulgados nos Estados Unidos há mais de cinco anos, artigos e livrostexto sobre sua aplicação à saúde mesmonaliteraturanorte-americana passaram a ser publicados basicamente a partir de 1990. 
2. AQUINO, C.P. de. Desenvolvimento:treinamento, planejamentode carreira e promoçāo. In: AQUINO, C.P. de. Administraçäo de Recursos Humanos: uma introdução. São Paulo, Atlas, 1979, p. 172

3. PIZARRO, P.R. de G. Prefácio. In: BOOG, G.G. (Org.) Manual de Treinamento e Desenvolvimento, São Paulo,McGraw Hill/Associação Brasileira de Treinamento e Desenvolvimento, 1980.

4. GARCIA, R.M. A base de uma administração autodeterminada: 0 diagnósticoemancipador. Revistade Administração Pública, 18(3):120-39, 1984. Neste artigo, 0 autor aproxima conceitos de Paulo Freire e de Antônio Guerreiro Ramos, com vistas a oferecer uma allernativa aos modelos funcionalistas tradicionais de se lidar com a organização.

5. NOGUEIRA, R.P. Dinâmica do Mercado de Trabalho em Saúde no Brasil, Brasília, Organização Panamericana da Saúde, 1986. ou dados observados, seja para explicá-los ou para modificá-los.

\section{DESENVOLVIMENTO DE RECURSOS HUMANOS}

A grande maioria dos livros-texto de Administração de Recursos Humanos, mesmo aqueles escritos há mais de dez anos, define Desenvolvimento de Recursos Humanos como algo diferente de treinamento, no sentido de que busca desenvolver os indivíduos não apenas para seu melhor desempenho nas tarefas que lhe são atribuídas pela organização mas também para suas condições de crescimento pessoal. Por exemplo, lê-se: "É necessário proporcionar ao funcionario oportunidades de desenvolvimento pessoal e profissional e condições satisfatórias de trabalho em todos os sentidos".2

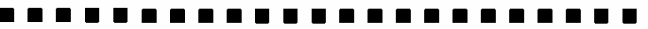 \\ Numa área como a de saúde, a omissão frente a aspectos referentes ao desenvolvimento dos recursos humanos é tender à negligência na prestação de qualquer dos tipos de serviços.}

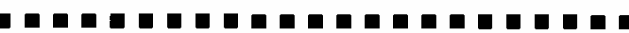

Certamente não é nova a discussão sobre o assunto, nem mesmo na realidade brasileira. É de 1980 a frase transcrita a seguir: "O treinamento e desenvolvimento de recursos humanos no Brasil, reconhecidamente, ainda não constitui preocupação prioritária na maioria das empresas..." ${ }^{3}$ A área de saúde, que não prima por ser das primeiras a incorporar as inovações administrativas, não foge à regra.

Neste contexto, a definição de administração como o processo de "conseguir coisas através de pessoas" termina por ser aplicada, de maneira praticamente acrítica, nas práticas do setor. Aparentemente esta definição, que pode ser considerada como utilitária, contradiz a proposta de desenvolvimento em seu sentido mais amplo. Com isto, a situação mais freqüentemente observada nas organizações do setor é a tentativa de ajustar indivíduos ou grupo às suas necessidades (conseqüentemente, consideram-se quaisquer condutas pouco satisfatórias como desviantes e passíveis de retificação frente àquelas ditadas pela organização).

Na verdade, uma análise organizacional um pouco mais aprofundada deve levar em conta as imagens dos recursos humanos em relação ao seu trabalho, a sua visão de futuro, a seu conceito de autoridade e ao seu "modelo de homem". ${ }^{4}$ Os diagnósticos de situação atual sobre a questão do desenvolvimento (e de todas as demais políticas) de recursos humanos não fazem mais que refletir as opções, conscientes ou não, feitas internamente a cada organização. No caso da saúde, isto chega até as opções do setor, feitas interna e, principalmente, externamente a ele, que se refletem nas políticas de financiamento, na imagem vendida pelos meios de comunicação e até, freqüentemente, nas prioridades setoriais. As denúncias feitas pelo $\mathrm{Sr}$. Ministro da Saúde, no início de sua gestão, no primeiro semestre de 1992, a respeito do papel das empreiteiras na formulação das políticas de saúde são um bom exemplo do descrito.

O quadro não é animador. Salvo algumas experiências como o chamado "Programa de Larga Escala", incentivado pelo Ministério da Saúde sob a orientação inicial de técnicos da Organização Panamericana da Saúde, poucos são os esforços realizados com os trabalhadores da saúde no sentido de sua capacitação além dos limites estritos da técnica (pode-se até dizer que as propostas de capacitação estritamente técnicas estão aquém da suficiência). Ressalvem-se, naturalmente, algumas das experiências de desenvolvimento gerencial em curso (mais uma vez, tema de moda na área), que são de interesse imediato das organizações e cuja população alvo costuma ter acesso a outras alternativas. A massa dos trabalhadores da saúde tem escolaridade baixa (em 1980, mais de $50 \%$ do chamado pessoal de enfermagem, categoria que representa perto de $30 \%$ dos postos de trabalho do setor, tinha curso primário incompleto $)^{5}$, ganha mal, tem mais de um emprego e pouca aderência para com seu trabalho.

Existe uma visão otimista de mundo que aponta para aqueles que optam pelo setor saúde como uma vocação, o que garantiria o aspecto de compromisso. No entanto, isto se dá quando a possibilidade real de opção 
profissional existe. Para a mão-de-obra menos qualificada, a rigor, o setor saúde é apenas uma grande fonte de empregos. Quanto aos profissionais universitários, pode-se dizer que o momento do apostolado já passou, bastando para isto observar as estatísticas a respeito da escolha de especialidades na área médica por parte dos récem-formados. Alguns autores, mais críticos, chegam a afirmar que a opção se faz à luz das tabelas de honorários vigentes.

Este tipo de quadro permite desenhar duas grandes linhas alternativas: ou dizer que as condições atuais não permitem que se pense em desenvolvimento de recursos humanos ou partir para o que é possível, criando condições para atividades cada vez mais abrangentes, dentro de um planejamento (compromisso?) de longo prazo. A primeira alternativa é imobilista, embora reflita, infelizmente, a conduta mais comumente observada. Apesar de ser a mais comum, sob princípios éticos e humanos é inaceitável. Faz parte do papel de qualquer administrador a mudança estratégica nas condições da organização, de modo a torná-la mais apta a desenvolver suas tarefas técnicas e a manter sua sobrevivência, não de qualquer modo mas sim atendendo cada vez mais e melhor as necessidades de sua população usuária. Numa área como a de saúde, na qual a população apresenta necessidades inquestionáveis, seja sob o ponto de vista técnico, seja considerando aquilo que ela busca junto ao setor, a omissão frente a aspectos referentes ao desenvolvimento dos recursos humanos é tender à negligência na prestação de qualquer dos seus tipos de serviço que lhe são potencialmente atribuíveis.

No fundo, é mister lembrar que só programas ligados à educação não esgotam em absoluto as preocupações de desenvolvimento de recursos humanos. Este deve levar em conta as condições em que o trabalho é exercido. Trata-se aí de condições técnicas, sem dúvida, mas também das relações entre a organização e seu corpo vivo, o que significa algum grau de preocupação com as condições de vida no trabalho, ou seja, carreira, salário, aceitação do trabalhador, antes de tudo, como ser humano. Na verdade, causa espécie ouvirse esta última hipótese, pois a premissa subjacente é que pode ser diferente, ou seja, pode-se esquecer da condição humana deste trabalhador, considerando-o como um insumo semelhante a qualquer outro.

\section{CULTURA ORGANIZACIONAL}

Até o início dos anos 80 , cultura organizacional era estudada por antropólogos e sociólogos como refletindo situações específicas. Em 1984 surge uma "nova" definição, com um caráter muito mais voltado à prática administrativa. Para Schein, cultura organizacional é o conjunto estruturado de pressupostos básicos que um determinado grupo inventou, descobriu ou desenvolveu ao aprender a lidar com os problemas de adaptação externa e de integração interna. Se estes pressupostos foram validados pela prática, devem ser ensinados aos membros da organização como a forma correta de perceber, pensar e sentir com relação àqueles problemas. ${ }^{6}$

Entendendo-se que a Teoria das Organizações seja influenciada pela prática gerencial, pode-se assumir que também esta necessidade de uma nova abordagem para a questão seja a resposta a problemas gerenciais identificados no cotidiano. De fato, observa-se que ela surge tentando enfatizar idéias comuns, valores e formas de se trabalhar com alguma identidade, como resposta, portanto, aos fenômenos observados de desintegração. Em última instância, como a sociedade se apresenta desintegrada, mas é muito difícil influir sobre ela, a organização pode e deve buscar alternativas de harmonização, por meio do consenso e da solidariedade. ${ }^{7}$

Desta forma, assumindo uma orientação prescritiva, as organizações se preparam para lidar com seus ambientes interno e externo utilizando instrumentos básicos como missão, objetivos concretos, realização em função destes, acompanhamento e reparo. Grosseiramente, pode-se dizer que estes intrumentos permitem que os indivíduos, nas organizações, tenham claro o que justifica seu trabalho, aquilo para o que trabalham, por que trabalham, como o fazem e onde. Para garantir ofuncionamento destes instrumentos, tornam-se necessários mecanismos comuns de compreensão, como linguagem compartilhada, definição clara e consensual a respeito dos limites da organização (no mínimo, quem
6. SCHEIN,E. Coming to a new awareness of organizational culture. Sloan Management Review, Winter, 1984.

7. FLEURY, M.T.L. Cultura Organizacional - os modismos, as pesquisas, as intervençōes: uma discussáo metodológica. Revista de Administraçăo, 24(1):3-9, 1989. 
8. MALIK, A.M. \& NEUHAUSER, D. Comportamentoorganizacional para administração de serviços de saúde. Revista de Administração de Empresas. 23(1):67-72, 1983. dela faz parte e quem não), alternativas internas de identificação de autoridade e status, critérios específicos de punições e recompensas e mecanismos organizacionais para lidar com imprevistos. ${ }^{8}$

Ou seja, além de se constatar, como dado de realidade, que as organizações têm culturas, é possível interferir sobre elas. A simples constatação do fato pode gerar imobilismo, como é comum observar em organizações mais estáveis, cujos membros têm um passado de convivência e de criação comum de significados e de valorização de eventos ocorridos. Nestes casos, freqüentemente se menciona que qualquer mudança é difícil, pois a cultura já está estabelecida, é aceita e até "pratica$\mathrm{da}^{\prime \prime}$. Na verdade, este é mais um mecanismo de defesa do grupo que definiu os pressupostos vigentes contra a necessidade de se reverem os mesmos frente a novas facetas da realidade. A validação destes pressupostos se deu, certamente, frente a uma dada realidade, mas esta mudou e, a rigor, junto com ela, podem mudar as relações de poder já confortavelmente estabelecidas, conhecidas e reconhecidas, frente às quais os atores organizacionais definiram mecanismos de sobrevivência.

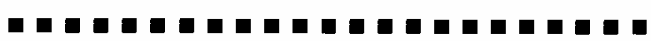

Todo o processo de produção pode - e deve-ser administrado, a rigor, desde antes de seu início.

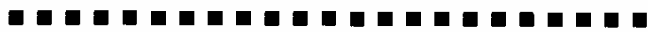

Ao mesmo tempo, é forçoso reconhecer que diversas organizações, entre elas aquelas da área de saúde, têm mais de uma cultura ou subcultura. Trata-se de reconhecer as diferentes maneiras pelas quais os componentes das organizações se relacionam com o universo interno. Nas organizações de saúde, como hospitais, por exemplo, verifica-se que as relações entre áreas-fim e áreas-meio são bastante díspares desde a própria compreensão de seu papel na organização. Não é incomum encontrarem-se profissionais da área de administração de recursos que se esquecem da especificidade da assistência médico-hospitalar, exceto no que diz respeito a considerar "rebeldes" grupos profissionais hegemônicos quando se trata de cumprir normas estabelecidas. Da mesma forma, há profissionais voltados à atividade assistencial que partem da premissa que a administração, por definição, serve para obstar os atos da nobre arte de salvar vidas, impondo constantemente limites e restrições sem sentido (para eles).

É necessário lembrar que a compreensão de cultura como categoria de análise ou como instrumento gerencial parte das opções do gerente. Desta forma, cabe o reconhecimento, alternativo, da cultura, seja como mais um entre os diferentes subsistemas que conformam a organização, seja como um determinante de todos os demais componentes. Além disto, é preciso levar em conta qual o papel da cultura organizacional e de sua eventual utilidade no sentido de se preverem os comportamentos emergentes da organização, frente à implantação de uma nova política interna ou de se desenhar e obter os comportamentos desejados para a viabilização da mesma.

Mais uma vez, como tema de "moda" na literatura gerencial, a cultura organizacional vem sendo vendida como uma maneira de se melhorarem os resultados da organização. Desta forma, cultura pode ser vista como um instrumento estratégico no sentido de garantir o alcance dos objetivos. Neste caso, qualquer mudança pode ser administrada, desde que se reconheça que ela deve passar pelo consenso e pode ser facilitada por atividades de desenvolvimento de recursos humanos na direção desejada. Não é plausível esperar que as mudanças possam ocorrer a curto prazo, mas é desejável que se assuma o fato de que a mudança é variável sempre presente no mundo.

Finalmente, percebendo que a condução da mudança por meio dos instrumentos de cultura pode ser útil no sentido de diminuir as incertezas e inseguranças dos atores organizacionais (atuando, portanto, como um potencial redutor na emergência de conflitos), é fundamental a noção crítica do processo. Ou seja, é inegável que a cultura como instrumento tem uma forte função de controle, seja dos comportamentos dos recursos humanos organizacionais, seja até mesmo no seu modo de pensar. A consciência dos trabalhadores não pode ser abafada a bem de uma nova política organizacional, por mais legitimada internamente que esta seja. 
No entanto, devido aos aspectos de criação de consensos e de tentativa de uniformização de valores, a cultura organizacional cai, freqüentemente, na utilização de instrumentos de educação que ultrapassam os cognitivos e psicomotores, atingindo os afetivos. Esta tentação, de ter funcionários intrinsecamente comprometidos com a organização, por vezes é muito forte para os gerentes. Isto só pode ser superado por meio da crítica (e autocrítica) constante.

\section{QUALIDADE}

Discutir sobre qualidade, hoje em dia, parte da premissa de que se sabe sobre o que se está falando. No entanto, isto não é necessariamente verdade. Uma das definições associadas ao que atualmente se denomina Administração da Qualidade parte do conceito de que qualidade é fornecer ao "cliente" aquilo que ele deseja. Surge, porém, um novo problema: quem é o cliente?

Existe uma grande diferença entre os conceitos tradicionais de avaliação e controle de qualidade e aquele que trabalha administração ou gerência de qualidade. $O$ novo pressuposto é que não se espera ter pronto um produto ou serviço para, depois, aferir se ele tem ou não qualidade. Pelo contrário, todo o processo de produção pode - e deve - ser administrado, a rigor, desde antes de seu início, partindo da premissa que se sabe o que se vai produzir ou oferecer enquanto serviço.

Para este tipo de gerência, a identificação do(s) cliente(s) e de suas expectativas é básica. No setor saúde, é comum chamarse, genericamente, cliente ao usuário final dos serviços produzidos, ou seja a população ou "os pacientes". No entanto, esta definição é, no mínimo, abrangente demais. Tomar "os pacientes" como um todo é assumir que trata-se de categoria homogênea, com as mesmas necessidades, em todos os âmbitos possíveis.

Este processo de despersonalização representa, ao mesmo tempo, uma das críticas mais comuns à maneira pela qual o sistema de saúde trata seus usuários e uma negação daquilo que os profissionais do setor alegam em sua defesa quando se tenta normatizar seu trabalho, o popular chavão "cada caso é um caso".
Sem dúvida, é à população que se destinam os trabalhos e, conseqüentemente, os processos do setor saúde. No mundo das organizações, porém, há clientes internos, não apenas da organização como um todo mas de todas as suas partes componentes. Assim, um serviço que lida com vigilância sanitária tem como clientes imediatos aqueles que devem (ou deveriam) trabalhar segundo as normas existentes e traçadas. Se estas normas forem pouco claras, como se pretende que elas sejam compreendidas? No próprio processo de definir as normas existem diversos clientes intermediários, que vão de algum modo participar de sua elaboração, de sua implementação ou do controle de seu cumprimento.

Neste caso, passa-se a entender a organização como uma série de consumidores e fornecedores sucessivos. Afinal, cada vez que se identifica um cliente, identifica-se simultaneamente um fornecedor de produtos ou serviços para eles.

Outra mudança de perspectiva necessária é a de que espera-se que as organizações - e, portanto, seus gerentes - se ponham a buscar, além de problemas a solucionar (geralmente voltados para o curto prazo), oportunidades de melhorar a qualidade de seus processos internos (o que significa, basicamente, expandir o horizonte de tempo com o qual se trabalha). Fundamentalmente, passa-se a ter a noção de que qualidade deixa de ser a responsabilidade de poucos atores organizacionais e passa a ser atribuição da organização como um todo.

Mais importante, deixa de ser um termo vago (como "Oferecer serviços da melhor qualidade possível") para tornar-se um conjunto de objetivos mensuráveis e buscados pela organização. ${ }^{9}$

Numa fase em que qualidade é o termo da moda, diversos autores se debruçam sobre ela para desenhar o novo paradigma. Na verdade, não se pode falar de novidade nas bases teóricas reais que norteiam os conceitos. Analisando os pressupostos da questão, verifica-se que, a rigor, eles retomam praticamente tudo o que já foi escrito sobre as Teorias de Administração e enfatizam alguns dos chamados métodos estatísticos de controle (de maneira até bastante simples, não fugindo, em seus aspectos básicos, daquilo que se denomi-
9. BERWICK, D.M.; GODFREY, A.B.\& ROESSNER, J. Curing Health Care. San Francisco, Jossey-Bass, 1991. 
10. DEMING, W.E, Qualidade: a revoluçāo da administração, Rio de Janeiro, Marques-Saraiva, 1990.

11. GUERREIRORAMOS,A. Modelos de homem e teoria administrativa. Revista de Administração Pública. 18(2):3-12, 1984

12. CAMPOS,A.M. Accountability: quando poderemos traduzi-la para o Português? Revista de Administração Pública, 24(2):30-50, 1990. nam medidas de tendência central).

A grande "inovação" está em tomaremse todas as teorias de forma integrada. Assim, trabalhando com um entre os autores mais citados na área, tomando-se os 14 pontos de Deming ${ }^{10}$, verifica-se que eles abordam planejamento e administração estratégica (quando se referem ao horizonte de tempo, à coerência entre as ações e às alternativas de implantação e viabilização). Ao mesmo tempo, retornam à chamada administração científica, quando analisam o processo em busca da "melhor maneira" de se trabalhar e quando se debruçam sobre aspectos fundamentais de treinamento e retreinamento técnico e para a qualidade. No caso, a grande diferença é não assumir $a$ priori o conhecimento desta melhor maneira, mas sim dar-se conta de que os trabalhadores envolvidos nos processos são quem melhor condição apresentam de aprimorá-los (emprestando, de algum modo, as premissas dos Círculos de Controle de Qualidade). A escola de Relações Humanas também é objeto de atenção, por meio de afirmativas como a de que é necessário afastar o medo reinante entre administradores e trabalhadores técnicos. As teorias de motivação têm seu lugar quando se trata de "eliminar as barreiras ao orgulho da execução".

A Teoria Geral de Sistemas tem lugar de destaque no desenho da proposta, uma vez que um de seus termos-chave é processo. Mais uma vez, porém, aparece uma diferença básica com seu entendimento mais usual. Neste caso, o processo deixa de sequer poder ser entendido como uma caixa preta, pois é de seu conhecimento em profundidade que partem as mudanças pretendidas. Ou seja, altera-se o conceito tradicional de que importa basicamente atingir os objetivos, seja por que processo for, uma vez que se percebe que a consecução dos objetivos depende direta e inequivocamente da maneira pela qual forem conduzidos os processos.

Finalmente, é necessário apresentar uma característica que nem sempre é levada em conta nas discussões a respeito da administração da qualidade. Afinal, é subjacente ao seu discurso o respeito pelo ser humano, seja enquanto consumidor (no caso da saúde, real ou ainda potencial) seja enquanto ator organizacional, assumindo um "modelo de homem" racional, dono de seu próprio destino dentro e, principalmente, fora da organização e de quem depende a qualidade daquilo que se produz. ${ }^{11} \mathrm{Com}$ isto, este modelo torna-se tentador em função de seus aspectos de nova relação entre trabalhador e organização.

Por outro lado, porém, todas as premissas administrativas sobre as quais se assenta o modelo são voltadas à redução de custos, à diminuição das perdas e do desperdício por intermédio da eliminação da necessidade de retrabalho frente à correção dos erros que levam ao trabalho mal feito. Ou seja, por mais que se diga que não se trata de buscar culpados, eles ainda são freqüentemente encontrados e tratados como tal. A rigor, a teoria é mais atraente que sua aplicação na prática, principalmente em organizações de grande porte, nas quais não existe a real garantia de entendimento das propostas, conforme preconizado no modelo, por toda a organização.

\section{DESENVOLVIMENTO DE RECURSOS HUMANOS, GERÊNCIA DE QUALIDADE E CULTURA DAS ORGANIZAÇÕES DE SAÚDE}

Frente às colocações acima, é impossível falar de gerência de qualidade sem considerar, em primeiro lugar, desenvolvimento de Recursos Humanos. As organizações que se conhecem, envolvidas no processo de implantação deste tipo de atitude (entendendo, portanto, gerência de qualidade acima de tudo como atitude), defrontam-se com a necessidade de desenvolver um novo "pacto" interno, em que a valorização do trabalhador é um passo inicial e prérequisito para qualquer seguimento. Desta forma, também se conhecem organizações que não conseguem desencadear o processo por recearem os investimentos necessários.

De fato, uma das primeiras constatações necessárias para se implantar a administração da qualidade é que Recursos $\mathrm{Hu}$ manos devem passar a ser vistos como investimento e não apenas, como é tão comum observar no setor saúde, como mais um item de custeio. A segunda se prende a uma nova noção de responsabilidade social (accountability) ${ }^{12}$, ou seja, à alteração da cultura do setor.

$\mathrm{Na}$ verdade, a saúde é uma das áreas em que os técnicos consideram menos neces- 
sário justificar quaisquer atitudes, uma vez que as organizações consideram deter o conhecimento, sendo cada área a dona absoluta de sua expertise. Desta forma, os médicos herdam o poder de seus pares e se assumem, em última instância, como responsáveis pela vida (nem sempre pelo bem-estar) de seus pacientes. Os enfermeiros respondem pelos procedimentos realizados e, em nome da qualidade, quase sempre se consideram abaixo do número ideal de profissionais de que necessitariam para melhorar o serviço prestado.

Desta forma, pode parecer que qualidade é função de quantidade de recursos humanos, sendo seu déficit um fator de imobilismo. Quadros de pessoal aumentados, em qualquer área, porém, nem garantem qualidade nem são vistos como satisfatórios. Pode-se até mesmo dizer que chegam a ser um obstáculo a um serviço mais adequado, pois favorecem a atomização do trabalho e a perda da visão do todo (sempre dentro de limites, bem entendido, pois existem de fato condições de inaceitabilidade observadas com alguma freqüência nas organizações do setor).

Tirando o foco dos hospitais, as informações a respeito de saúde dirigidas à população em geral não costumam atingir seu alvo. Por isto, por exemplo, a necessidade de campanhas de vacinação, maciçamente divulgadas e caras, para suprir a deficiência de programas de sensibilização em relação à imunização como necessidade e como atividade rotineira (mais uma vez, ressalvados os aspectos técnicos específicos voltados à imunização). $\mathrm{O}$ mesmo se pode dizer com relação a aleitamento materno, direitos em relação à saúde etc. Cabe ainda lembrar que o termo "população em geral" inclui boa parte dos trabalhadores da área, que freqüentemente ignoram o que não seja diretamente relacionado a suas tarefas específicas.

Assim, o novo conceito de responsabilidade social prende-se ao fato de os profissionais do setor assumirem seu papel na informação à população, com dados reais e numa linguagem acessível. Isto pode ser considerado óbvio. No entanto, entra aí também a questão dos custos. Estudos norte-americanos mostram que consumidores bem informados passam a optar conscientemente entre diversas alternativas de conduta médica e até de investiga- ção diagnóstica que lhes são oferecidas, quando o serviço cessa de tomar decisões em seu nome, sem conhecer suas reais expectativas. Alguns serviços, enquadrados na categoria da assistência médica supletiva, como autoprogramas, apregoam como grande vantagem na racionalização do consumo de serviços por parte de seus beneficiários o conhecimento que estes possuem a respeito de preços de diferentes procedimentos.

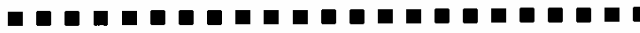 \\ Seguir receitas é arriscado, quando não danoso. A criatividade deve ser a bússola da organização, se $e$ quando esta considerar oportuno mudar sua cultura para oferecer serviços mais adequados às necessidades percebidas.}

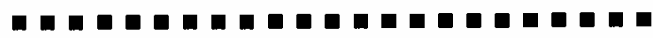

O grande motivador deste processo de informação (ou de, no mínimo, prestação de contas) nos Estados Unidos são os financiadores da área da saúde, que passam a querer saber pelo que pagam. ${ }^{13}$ No Brasil, onde o maior financiador da assistência médica continua a ser a Previdência, não se pode ainda dizer que os critérios de remuneração passem pelo conhecimento dos procedimentos prestados, salvo em algumas iniciativas isoládas como é o câso dos centros de excelência envolvendo áreas como Oncologia, Traumato-Ortopedia e Cardiologia.

Estas ponderações valem também para os financiadores privados que, embora tenham sistemas de controle mais eficazes, não necessariamente entram no mérito da real necessidade dos procedimentos realizados. Até que ponto, no entanto, as normas existentes resolvem o problema? Até que ponto os responsáveis pelas normas consideram seus usuários como clientes? Pelo contrário, são bastante usuais os protestos dos profissionais, principalmente os médicos, no sentido de considerarem as normas como "padrões mínimos", impedindo-os de utilizar todos os avanços da ciência médica a serviço do paciente...

Passa-se aí a ter que considerar questões relativas à ética,.cujos limites são extrema-
13. BERWICK, D.M.; GODFREY, A.B. ROESSNER, J. Op.cit, p.4. 
14. DONABEDIAN, A. A guide to medical care administration. Vol. II. Washington, AUPHA, 1975.

15. COUCH, J.B. (Org.) Health care quality management for the $2 f^{s t}$ century. Tampa, American College of Physician Executives, 1991.

16. BURMESTER, H. \& BERTOLUCCI, R. $O$ programa de avaliação da qualidade do atendimento médico-hospitalar do Estado de São Pauloda Associação Paulista de Medicina. mimeo, 1991.

17. PROAHSA - Programa de Estudos Avançados em Administração Hospitalar e de Sistemas de Saúde. Manual de organização e procedimentos hospitalares. Säo Paulo, Pioneira, 1987. mente delicados. Este não é um aspecto passível de ser considerado em poucas linhas e portanto, só está sendo apontado como lembrança. De qualquer forma, estes contornos já foram trabalhados, com bastante ênfase, há décadas, por Donabedian, autor tradicional do campo de conhecimento da Avaliação em Saúde. ${ }^{14}$

Por outro lado, nos EUA já há um forte movimento no sentido de tentar viabilizar a administração da qualidade como prática corrente na área de saúde, seja para racionalizar custos, seja para manter/adquirir mercado, seja apenas para evitar processos legais. O Colégio Americano de Executivos Médicos (American College of Physician Executives) publicou, em 1991, um livro no qual tenta enxergar até o século XXI, no qual se preocupa com forças ambientais que afetam a gestão da qualidade, com a emergência e com a formulação de novos parâmetros e apresenta situações concretas de implantação da nova filosofia. ${ }^{15}$

No Brasil, também se verifica a preocupação das associações médicas com esta problemática. Em São Paulo, a Associação Paulista de Medicina, por intermédio da Sociedade Médica Paulista de Administradores de Saúde, desenvolveu um Programa de Avaliação da Qualidade do Atendimento Médico-Hospitalar do Estado de São Paulo (CQH - Controle de Qualidade Hospitalar) que, embora não se apóie claramente nas linhas tradicionais de administração de qualidade, certamente trabalha questões da cultura dos hospitais. Um dos primeiros sintomas a este respeito é que se trata de um programa voluntário, que busca a adesão das instituições que desejem trabalhar a questão. Em segundo lugar, vem a tentativa de não visar a classificações, mas sim de buscar a sistematização de instrumentos de medida de qualidade, ainda em desenvolvimento e certamente não consensuais. $O$ terceiro (e mais estranho à realidade brasileira) vem com a premissa de que, se a preocupação com a qualidade existe, não se corre o risco de haver, por parte das organizações que aderirem à proposta, qualquer tipo de manipulação de dados. ${ }^{16}$

Esta é, sem dúvida, uma nova forma de se olhar para a qualidade abandonando a postura policial externa de avaliação/auditoria, controlista e punitiva, em favor de uma atitude interna, prospectiva, autoavaliativa e, fundamentalmente, educativa. Uma das formas de se tentar trabalhar estes aspectos está, por exemplo, na manualização. Manuais não são novidade na prática administrativa, mas sua utilização costuma estar longe daquela teoricamente preconizada. Já existem propostas genéricas de manuais de organização e rotinas hospitalares à disposição daqueles que se interessam por modelos. ${ }^{17}$

No entanto, não se trata, certamente, de tomar manuais já prontos e copiá-los, atitude não incomum em nosso meio. Pelo contrário, quer-se propor que se veja na elaboração de rotinas um mecanismo para estudar aquelas já existentes, à luz de sua adequação a cada situação e, eventualmente, a aspectos técnicos apresentados nos manuais teóricos. A elaboração coletiva de rotinas, sua utilização no dia-a-dia e em programas de educação e treinamento dentro da organização, além de sua atualização sempre que necessário, tendem a mudar a prática. Atualmente, quando há manuais atualizados, verifica-se sua utilização basicamente como mecanismo de avaliação/cobrança. A nova visão assume que o instrumento pode estar pouco adequado, sendo, portanto, passível de correção e adaptação.

A rigor, isto traz em si uma noção pouco usual no setor saúde, voltada para "administração de desempenho", a ser contraposta à avaliação de desempenho, atomizada, periódica e, freqüentemente, realizada sobre critérios obscuros, se não para o avaliador certamente para o avaliado. A explicitação de critérios organiza o trabalho, oferece direção ao trabalhador $\mathrm{e}$ permite que se perceba o conceito de "parceiros" intra-organizacionais, talvez mais claro que o de clientes internos. A quantidade de hospitais onde diferentes serviços são vistos, uns pelos outros, como obstáculos e não como facilitadores fala muito a favor da necessidade de se operacionalizarem novas relações de trabalho.

\section{CONCLUSÕES}

Desta maneira, administração da qualidade em saúde implica em mudança na cultura do setor. Como qualquer mudança de cultura, seu horizonte de tempo é o longo prazo. Mais que isto, trata-se de um 
compromisso a ser conduzido constantemente.

Em última análise, é a busca de explicitar uma aliança teoricamente tácita entre o setor (por intermédio de suas organizações) e a população, que necessita passar por um processo aberto interno às organizações. Diz a teoria que administração da qualidade não deve ser implantada em partes isoladas da organização. Pelo contrário, sem o compromisso da cúpula dirigente pouco será alcançado. Mais uma vez, segundo os livros-texto, é imprescindível envolver toda a organização, de seus escalões superiores até os inferiores.

A realidade observada, principalmente no setor saúde, no Município de São Paulo, mostra que estes dogmas podem ser relativizados. Em um dos hospitais que vem trabalhando com esta idéia, a movimentação partiu dos médicos e vem se espalhando, de maneira atomizada, pela organização, que já começou a trabalhar com a perspectiva de adequar sua política de recursos humanos à nova realidade. Noutro, o programa surgiu por iniciativa do órgão de Recursos Humanos, que preparou um programa preliminar em fase de negociação com a administração superior. Noutro ainda, se está trabalhando em uma das áreas-meio, na tentativa de se obter um efeito demonstração que convença os dirigentes a desencadearem alguns dos esforços necessários para que a idéia tome corpo. Em organizações voltadas à produção de insumos, nas quais a racionalidade administrativa é diferente daquela prevalente nos serviços, já se têm compromissos institucionais e processos muito mais avançados no tempo, contando com anos de evolução.

Qualquer iniciativa parece válida, neste momento inicial. É mais fácil entender-se a lógica dos princípios da gerência de qualidade em fábricas, pois em organizações de serviços, a rigor, os produtos são muito menos precisos. Por isso, a área de prestação de assistência à saúde e, dentro dela a de assistência médico-hospitalar, vem sendo abordada com mais cautela.

A administração da qualidade não é receita, nem deve ser encarada como modismo. Por mais que seus princípios, como tantos outros, não pareçam inovadores a todos, por mais que se tenha a impressão de que tudo já foi tentado, reveste-se hoje com este rótulo a tentativa de se reverter aquilo que, neste momento, não satisfaz nem aos trabalhadores do setor nem a seus usuários.

Por isto, seguir receitas é arriscado, quando não danoso. A criatividade deve ser a bússola da organização, se e quando esta considerar oportuno mudar sua cultura para oferecer serviços mais adequados às necessidades percebidas. As técnicas já desenhadas são, sem dúvida, úteis, mas não são mais que técnicas. Neste caso, o fundamental são os princípios, entre os quais os éticos, que devem sair dos discursos e chegar às práticas.

Um dos pontos de Deming aponta justamente para isto: trata-se de adotar de fato a nova filosofia, e não brandi-la como um estandarte de comportamento adequado, apenas para abrir novos segmentos de mercado, obter novos financiamentos e cooptar seus novos e antigos trabalhadores.

Administradores do setor saúde devem assumir que a necessidade por qualidade como entidade definível existe e que faz parte de seu papel a criação de um ambiente que facilite sua obtenção. Em última instância, isto significa interferir sobre a cultura da organização de modo a partilhar com todo seu corpo vivo a responsabilidade pela qualidade. Ou seja, qualidade se torna indelegável. ${ }^{18}$

$\mathrm{Na}$ verdade, isto ainda requer uma dose de humildade, no sentido de reconhecer a ignorância que existe a respeito. Até o momento, não se pode falar a respeito de todas as competências necessárias nem de todos os componentes da qualidade em saúde, porque se conhecem poucas experiências, estas tendem a ser diferentes entre si e seu período de desenvolvimento pode ser considerado curto. Ou seja, elementos que permitam discriminar o que se deve a o que, em termos de sucesso ou de fracasso, não estão claros.

O que certamente está claro é que se trata de um processo de longo prazo, para o qual quase todos os esforços estão por ser desenvolvidos. Discutir questões administrativas sem estabelecer (novos) parâmetros assistenciais e/ou de resultados será aplicar de forma parcial um instrumento e mais uma vez defender a falácia de que a tecnologia administrativa não é aplicável/aplicada ao setor saúde. $\square$
18. FILERMAN, G.L. \& GELMON, S.B. Teaching management competencies for quality improvement. Association of University Programs in Health Administration, mimeo, 1992. 